\title{
Correction to: Investigating the Applicability of Blockchain Technology and Ontology in Plastics Recycling by the Adoption of ZERO Plastic Model
}

\author{
R. Sandhiya ${ }^{1}$ [ $\cdot$ Seeram Ramakrishna ${ }^{2}$
}

Published online: 10 June 2021

๑) Springer Nature Singapore Pte Ltd. 2021

\section{Correction to: Mater Circ Econ (2020) 2: 13 \\ https://doi.org/10.1007/s42824-020-00013-z}

The article Investigating the Applicability of Blockchain Technology and Ontology in Plastics Recycling by the Adoption of ZERO Plastic Model, written by R. Sandhiya and Seeram Ramakrishna, was originally published online on December 9, 2020 with Open Access under a Creative Commons Attribution (CC BY) licence 4.0.

After publication in volume 2, issue 1, page 13 the author(s) decided to cancel the Open Access. Therefore, the copyright of the article has been changed on April 2021 to

(C) The Author(s), under exclusive licence to Springer Nature Singapore Pte Ltd. part of Springer Nature 2021 with all rights reserved.

Publisher's Note Springer Nature remains neutral with regard to jurisdictional claims in published maps and institutional affiliations.

The original article can be found online at https://doi.org/10.1007/ s42824-020-00013-z.

R. Sandhiya

rsandhiya@cit.edu.in

Seeram Ramakrishna

seeram@nus.edu.sg

1 Department of Information Technology, Coimbatore Institute of Technology, Coimbatore, India

2 Department of Mechanical Engineering, National University of Singapore, Singapore, Singapore 